INTERNATIONAL DESIGN CONFERENCE - DESIGN 2018

https://doi.org/10.21278/idc.2018.0113

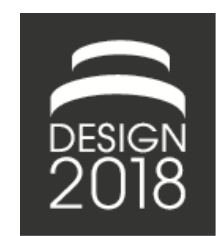

\title{
DO BETTER SKETCHERS BECOME BETTER PRODUCT DESIGNERS?
}

\author{
J. A. M. Corremans, K. R. Vaes and W. Coppieters
}

\begin{abstract}
The importance and value of sketching as part of the creative design process has already been extensively argued. Not only the act of sketching and the number of sketches made have a positive effect on the quality of the design outcomes, also sketch quality has an influence. The correlational study presented in this paper explores the relationship between the students' sketch courses grades and the grades for their individual design outcomes. The results show that students with better sketch competences are more likely to score higher for their product design projects.
\end{abstract}

Keywords: industrial design, design education, engineering design, sketching

\section{Introduction}

Multiple researchers, (Ullman et al., 1990; Goldschmidt, 1991; Schutze et al., 2003; van der Lugt, 2003; Ainsworth et al., 2011) underline the value of sketching in the design process and its importance in the generation, the communication, and the evolution of ideas. In the ideation phase, sketches are not a goal in itself, but a tool to make better designs (Waanders et al., 2011). Sketches are used as a source of inspiration, to assess idea quality and creativity, and the whole process of iterative sketching helps in structuring, developing and communicating the design process. But not only the act of sketching influences the development process, also the quality of sketches has an impact. Kudrowitz and Wallace (2013) concluded that a design idea presented by a high quality sketch is more likely to be ranked as the most creative idea when compared to a sketch of the same idea drawn with lower quality. Based on the analysis of the results of a brand extension design project experiment, Mulder-Nijkamp and Eggink (2016) found a significant Pearson correlation of 0.74 between the level of quality of drawings and the success of brand extension design outcomes, and thus that designs presented by drawings with a high level of quality highly correlated with the level of success.

Can we assume, regarding the findings above, that possessing good drawing skills make better designers? By proposing the hypothesis 'better sketchers become better product designers', we want to investigate whether there is a link between the quality of sketches and the quality of design outcomes.

This paper explores the relationship between the grades of the students' Sketch \& Spatial and Visual Thinking course of the 2nd Bachelor year and the grades of their individual product design project courses of the 2nd and 3rd Bachelor and the 1st and 2nd year Master programme. If the sketch scores of the second year (as representations of sketch quality) correlate significantly with the scores of design projects (as representations of design quality), than this could be an indication that the better sketchers are more likely to produce better design outcomes. 


\section{The role of sketching in the industrial design process}

The role and importance of hand drawing and sketching in the early stages of the design process has already been extensively argued. Sketching helps you to generate concepts quickly and to explore alternatives rapidly. Sketching provides a unique space that can help you think differently and encourages constructive discussions with colleagues and clients (Rohde, 2011). Self-made sketches support the limited human memory capacity and mental processing for a detailed problem analysis (Ullman et al., 1990; Pearson et al., 1996; Purcell and Gero, 1998; Suwa et al., 1998b; Kavakli and Gero, 2001). A laboratory experimental study (Schütze et al., 2003) pointed out that, in a group of mechanical engineering students, subjects who solved the design problem partly supported by sketching achieved a significantly higher solution quality of design outcomes in the early stages of the design process compared to those whose problem solving was entirely mental. According to Yang and Cham (2007) the impact of sketch skills in product design is higher than the impact of sketch skills in engineering design: in a project with the focus on engineering design Yang and Cham found that overall prolific sketchers were no more likely to have good design outcomes than those who did not sketch as much. Song and Agogino (2004) support the finding of Yang and Cham (2007) by finding significant correlation between sketch volume and design outcome in a product development course. It seems logical to assume that the impact of the aesthetic quality of sketches play a more significant role in judging design outcomes in product design, that in engineering design, because an important part of the sketches in product design are not limited to study merely functional or technical aspects, but also focus on the aesthetic aspects, details and form giving.

Other researchers focus on analysing the cognitive processes in design sketches (Suwa et al., 1998a; Dillon, 2010) and the impact on sketch results based on differences between traditional pen-and-paper sketching and CAD drawing/visual sketching software. Results of an experiment by Bilda and Demirkan (2003) show that traditional media have advantages over digital media regarding attention to, and reaction to visuo-spatial cues, specifically the relationship between elements in the design, and the quantity and variety in problem solving methods to address the design goals. On the other hand, in a more recent study Tang et al. (2011) concluded that the digital sketching environment is similar to freehand sketching in all significant aspects of the design process, including the speed of the design process, design issues concerned in the design processes, and the transitional activities.

\section{The impact of sketch quality}

Although extensive research underlines the importance of sketching, only limited research focus on the impact of the quality of sketches. While Rohde (2011) pretends that you don't have to worry how well you draw, or that the artistic quality of your sketches is not the point because the real goal of sketching is functional, Kudrowitz et al. (2012) conclude that there is more in a sketch than merely the creative idea: in addition to the creative merit of an idea in itself, the presentation of the idea may also affect the perceived creativity. In a design experiment where 360 reviewers ranked four different toaster ideas for creativity, referring to a set of four sketches by four people with different backgrounds and levels of sketching proficiency, Kudrowitz et al. (2012) explored the relationship between the quality of a product-idea sketch and how others perceive the creativity of the idea portrayed by the sketch. They concluded that high quality sketches were on average 2.3 times more likely to be ranked as the most creative idea when compared to sketch of the same idea drawn with lower quality. Lowest quality sketches were on average 2.4 times more likely to be ranked as the least creative idea when compared to the high quality sketch of the same idea. This statement was supported by Chan and Chan (2007) and Chan and Zhao (2010) who found correlations between sketching ability and artistic creativity suggesting that people who are good at drawing are also creative, and that drawing training in itself makes people more creative (Chan and Zhao, 2010). A possible explanation for this is that high quality sketches of products need less interpretation to be understood, so the person looking at the sketch can focus on analysing the creativity of the idea itself, rather than attempting to interpret the sketch in a meaningful way. A good sketch might be easier for the reviewer to imagine what the product would be like to use or exist in their own environment. Another possible explanation why ideas presented with high quality sketches are perceived more creative, is that we simply prefer and value things that are aesthetically pleasing. Donald Norman (2002) discussed the effect of pleasing design before, and argued that attractive things work better. Based on a study from the early nineties in Japan of cash dispenser interface designs, Kurosu and Kashimura (1995) claimed that beautiful 
and attractive products work better than ugly ones. Tractinsky (1997), an Israeli scientist, was very sceptical about this experiment and assumed that this result was due to the impact of Japanese culture with its strong aesthetic tradition. He repeated the same survey in Israel and deduced that the results were even more pronounced. And demonstrated that the perception of beauty having a positive impact on the experience of product effectivity transcends intercultural context differences. The final conclusion was the same: beautiful products work better. Also other researchers found correlations between ratings of attractiveness and ratings of creativity (Christiaans, 2002), or that the category of affect is the strongest indicator of willingness to purchase (Horn and Salvendy, 2009).

If aesthetics affect the evaluation of the final product or prototype, it is reasonable to assume that aesthetics also have an effect on the evaluation of the initial ideas, and that ideas sketched with higher quality will be perceived as more attractive. By the same logic, and considering that there always might be a risk that the quality of the sketch overpowers the quality of the idea, we could assume that the better sketchers will also be perceived as the designers with better design outcomes. An assumption supported by Mulder-Nijkamp and Eggink (2016) who found a significant correlation between the level of quality of drawings and the success of design outcomes in a brand extension industrial design project at the University of Twente.

\section{Do better sketchers become better product designers?}

The question 'Do better sketchers become better product designers' was suggested before by Song and Agogino (2004) in terms of: does a student's sketching skill impact the quality of the design outcome? Translated to the educational context, and starting with the premise that the grades of student design projects are a benchmark for design quality, and that the grades of students' sketch courses are a benchmark for sketch quality, we can research whether any correlations exist between these parameters. If sketch scores correlate with product design projects scores, one could conclude that the hypothesis that enhanced sketching skills improve the quality of the design solution can be supported.

\section{Grades as indicators of quality}

In an industrial context quality is never expressed in scores, but in education, scores a generally accepted as the benchmark for quality. Faculty and staff judge students' drawing skills and other design competences based on design outcomes like portfolios and projects. Teachers and tutors often combine jobs as professional designers in industry with a job in design education. They are specialists with a clear view on design skills and design quality and are experienced in translating students' outcomes into grades. In this study, grades (counted in whole points) are used as indicators of design quality.

\section{Correlational study}

This paper explores the relationship between the sketch grades of the students' sketching course of the 2nd Bachelor year and the grades (both expressed by a score between 0 and 20) of all of the individual product design project courses of the study Product Development of the Faculty of Design Sciences at the University of Antwerp.

\section{Methods and test bed}

Subjects

The sample was composed of 121 students (50 female and 71 male) of 3 consecutive graduation years (2012 - 2013, 2013 - 2014, 2014- 2015). Students who graduated with a research design project were omitted. Students who never graduated were ignored. Subjects were trained through their curriculum on a comparable level. Homogenous conditions could thus be assumed.

\section{Individual courses included in the study}

To avoid contamination of quality by fellow students, no group design assignments were included. All individual design project courses in the curriculum of the 2nd and 3rd Bachelor year and the 1st and 2nd Master year are taken into consideration. 


\subsection{Ten courses are included in the study:}

\subsubsection{The reference course for the correlational research}

S\&SVT - Sketching and Spatial \& Visual Thinking - 2Ba - 3ECTS

Sketch grades of novice designers (1st Bachelor year) were not considered, since former research pointed out that it appears that sketching may not be as helpful for novices in the development of new ideas, as it is for expert designers (Goldschmidt, 1991; Suwa and Tversky, 1997; Verstijnem et al., 1998; Casakin and Goldschmidt, 1999; Menezes and Lawson, 2006). Basic sketching skills are taught in the first and second semester of the 1st Bachelor year, so one can suppose that students of the second Bachelor have at least one year of experience and have built up a certain degree of expertise. The content of the course is focused on explorative and ideation sketches as a combination of visual representations of first ideas and a means of communication between the designer and other stakeholders. The artistic value of ideation sketches as such is not a prerequisite, but readability and communicative value is enhanced by the use of a well-constructed perspective, a clear line setting and sufficient detail. Figure 1 shows some outputs of this course: a combination of product observation and form ideation sketches. The requested output level are line drawings in pencil or fine liner with subtle shading to suggest 3D form. Colours are used to illustrate certain details. This level of sketching is earlier defined as sketches of level 4 on a scale of 5 (Rodgers et al., 2000).

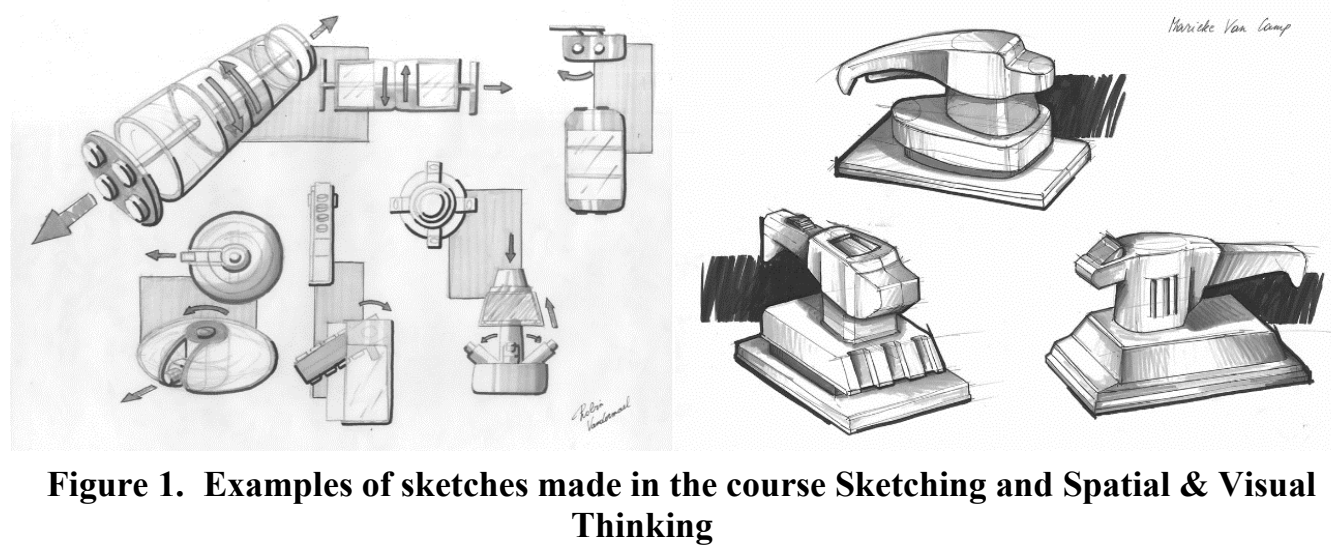

Assessment is based on a practical test and a drawing portfolio. Final scores are determined by an average score of four members of the teaching staff, taking into account sketch quality criteria as described by Alvarez (2004), Olofsson and Sjolen (2005) and Eissen and Steur (2007) as a combination of mastery in line-work execution, correctness of perspective, and appropriateness or realism of proportions. Sketch quality criteria are specified before with more detail: Kudrowitz et al. (2012, p. 270) describe line quality as a low amount of wiggle or tremor and a low amount of hash marks, correctness of two-point perspective as the technical execution of perspective: having lines converge to a set of vanishing points, having vertical lines drawn vertically, having circular shapes drawn with correct ellipses, and proportion as addressing the relative size of different features/dimensions within and object, and between different objects.

\subsubsection{Six individual design projects courses}

$\mathrm{RD}$ - Redesign - $2 \mathrm{Ba}-4$ ECTS

Design project course with focus on form creativity, aesthetics and the integration of an existing technical component.

MD - Mechanical Design - 2Ba - 3 ECTS

An engineering design project course with focus on mechanical components and the mutual interaction of mechanical subsystems within a larger configuration.

F\&C - Form and Colour - 2Ba - 3 ECTS 
Design project course with focus on form creativity based on personas and archetypes. Special attention is paid to all form giving aspects: contemporary design, proportion, aesthetics, form details, textures and colours.

BP - Bachelor Project - 3Ba-14 ECTS

The objective of the bachelor thesis is to develop a new product, based on a given product idea or system design within a specific business context. The emphasis is on the integration of different aspects within the relevant disciplines: multidisciplinary analyses, usability, aesthetic appearance, use of materials, technical and mechanical construction and verification techniques.

FOMA - Focus on Mechanical Aspects - 1Ma - 13 ECTS

The objective of this design project course is to develop solution strategies for and advanced skills in complex system design and to design a complex intelligent product integrating mechatronics, sensors and actuators and robotics. The expected level of design result is a detailed design.

$\mathrm{MP}$ - Masters Project - 2Ma - 28 ECTS

The Masters Project course is the final graduation project of the study Product Development. This 28 ECTS course goes beyond the design of a product or product-service combination. All aspects of a product development cycle are discussed and assessed: new products planning and ideation, extensive analysis, marketing aspects, applied research, verification; business planning, etc. In comparison to the other design project courses, the proportion of the component product design takes a smaller part in the full course.

The assessment of the design projects was done by juries composed of teaching staff and extern design experts. The composition of the jury varies from project to project. Assessment criteria vary depending on the focus of the initiated projects. Final grades are based on design outcome documents like design logbooks, technical documentation and presentation material like computer renders and models. Assessment of the final Master Project includes several juries spread over the project. Juries are composed of teaching staff, external promoters, doctors of sciences, and representatives of possible involved companies (engineers, marketing specialists, designers).

Depending on the project, the summative evaluation is based on scoring guidelines or rubrics. The application of rubrics in grading students' work is supported by Jonsson and Svingby (2007) who concluded that the use of rubrics improves inter-rater reliability and enhances reliable scoring of performance assessments.

In all of the courses, except for the course Sketching and Spatial \& Visual Thinking, sketches or sketch quality as such is not included in the assessment of the design projects. Evidently students use sketches in the course of their design process, and these sketches probably influence the final result, however, a separate score for quality or the amount of sketches is not incorporated in the assessments. The quality of the ideas behind the drawings was also not assessed separately, although one could assume that they were taken into consideration in the overall appreciation of the design.

\subsubsection{Three supportive theoretical courses}

By means of objectification, in order to neutralize the possible impact of the generally better students, three supportive theoretical courses were included in the study:

$\mathrm{PH}$ - Physics - 2Ba - 3ECTS

A 2nd Bachelor theoretical course with focus on the operating principles of momentum, angular momentum, general rotation, fluids, vibrations, waves, temperature and heat; imaging (interference, diffraction, refraction).

ER - Ergonomics - 2Ba - 3ECTS

Theoretical course supporting the understanding of physical, sensory and cognitive ergonomics.

M\&MR - Marketing \& Market Research - 3Ba - 3ECTS

Theoretical course with focus on market research techniques and introductory marketing skills.

The assessment of these courses is done by teachers and is based on theoretical exams and written papers. The minimum score to pass for all courses is 10 (on a maximum of 20). With a score of less than 10 , the student fails and can try to succeed through a re-examination. If he/she fails the re-examination, the student must retake the course in the next academic year. 


\section{Method}

Subjects were ranked according to their scores for the course Sketching S\&SVT. Subjects were then divided in 4 clusters.

Cluster A: sketch scores 10 or 11 (of the maximum of 20). This score level can be described as: possessing minimal sketch competences $(n=24)$

Cluster B: sketch scores 12 or 13. Level: adequate or average sketch competences $(n=47)$

Cluster C: sketch scores 14 or 15 . Good or distinct sketch competences $(n=37)$

Cluster D: sketch scores 16 or more: excellent sketch competences $(n=13)$

The scores of all the involved courses are listed in Table 1. Figure 2 shows a graphical representation of the conduct of the examined scored courses with the score of S \& SVT as a reference.

Table 1. Scores of the courses

\begin{tabular}{|c|c|c|c|c|c|c|c|c|c|c|}
\hline & S\&SVT & RD & F\&C & MD & FOMA & BP & MP & PH & ER & M\&MR \\
\hline $\mathrm{n}=24$ & 10 or 11 & 12,10 & 12,60 & 12,83 & 12,65 & 11,57 & 13,40 & 11,33 & 11,88 & 12,63 \\
\hline $\mathrm{n}=47$ & 12 or 13 & 12,94 & 12,96 & 12,36 & 12,55 & 12,03 & 13,64 & 11,54 & 12,65 & 13,30 \\
\hline $\mathrm{n}=37$ & 14 or 15 & 13,59 & 13,73 & 13,57 & 13,09 & 12,73 & 14,00 & 14,08 & 12,89 & 13,65 \\
\hline $\mathrm{n}=13$ & $\begin{array}{c}16 \text { and } \\
\text { more }\end{array}$ & 14,31 & 14,38 & 14,08 & 14,08 & 13,27 & 13,92 & 12,15 & 12,85 & 13,46 \\
\hline
\end{tabular}

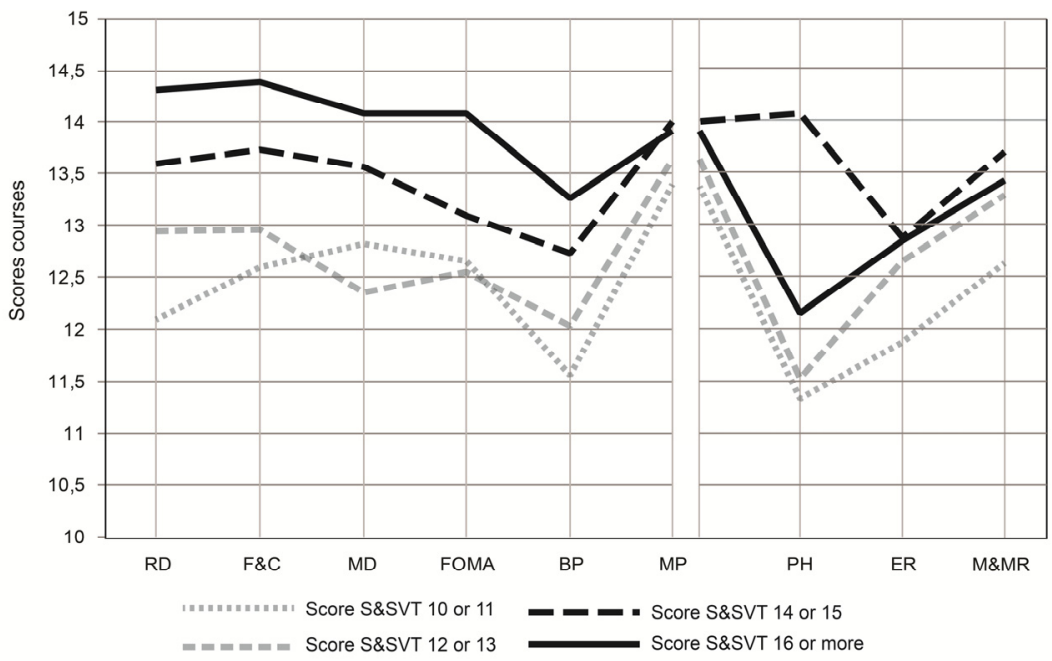

Figure 2. Scores of courses in relation to score S\&SVT

\subsection{Analysis of the results}

Effect of score for the sketching course (S\&SVT) on scores for other courses.

An ANOVA is used to explore the effect of the students' score-cluster for the course Sketching and Spatial \& Visual Thinking on the score for design project courses and theoretical courses.

The one-way analysis of variance (ANOVA) is used because it is commonly known as a good technique to determine whether there are any significant differences between the means of three or more independent (unrelated) groups (Leard Statistics, 2013).

The results of the ANOVA show a significant effect on the scores of four of the six design projects courses: Redesign $(\mathrm{F} 3,11=4.978, \mathrm{p}<.005)$, Form \& Colour $(\mathrm{F} 3,117=3.515, \mathrm{p}<.02)$, Mechanical Design $(\mathrm{F} 3,117=2.732, \mathrm{p}<.05)$, and Focus on Mechanical Aspects $(\mathrm{F} 3,107=3.451, \mathrm{p}<.02)$.

The ANOVA shows no signification for the Bachelor Project (BP) and the Masters Project (MP); $\mathrm{BP}(\mathrm{F} 3,98=2.541, \mathrm{p}=.061)$ and $\mathrm{MP}(\mathrm{F} 3,117=1.662, \mathrm{p}=.179)$

The ANOVA shows no significance for the theoretical courses Physics $(F 3,117=0.543, p=.653)$ and Ergonomics $(\mathrm{F} 3,116=1.342, \mathrm{p}=.264)$. 


\subsection{Objectification of the correlations}

By means of objectification, in order to neutralize the possible impact of the generally better students, the correlation between all the courses we consider in this experiment is explored (Table 2).

Table 2. Overview of the correlation between all courses

\begin{tabular}{|l|l|l|l|l|l|l|l|l|l|c|c|c|}
\hline & & S\&SVT & RD & MD & F\&C & BP & FOMA & MP & PH & ER & M\&MR \\
\hline S\&SVT & r-value & & .369 & .275 & .341 & .309 & .318 & .178 & .113 & .154 & .186 \\
& sig. (2-tailed) & & .000 & .002 & .000 & .002 & .001 & .050 & .219 & .092 & .041 \\
& n & & 121 & 121 & 121 & 101 & 111 & 121 & 121 & 120 & 120 \\
\hline
\end{tabular}

\subsection{Overview of the correlation between all courses}

Note: The reason the n-value for Bachelor Project and Focus on Mechanical Aspects is different, is that some students in their 3rd year Bachelor or their 1st Ma have been on Erasmus exchange.

We notice a significant positive correlation at 5 per cent significance level, between the results for sketching course and five off the six design project courses; Redesign $(r=.369, \mathrm{p}<.0005)$, Mechanical Design $(r=.275, \mathrm{p}<.005)$, Form \& Colour $(\mathrm{r}=.341, \mathrm{p}<.0005)$, Bachelor Project $(\mathrm{r}=.309, \mathrm{p}<.0005)$, Focus on Mechanical Aspects $(r=.318, \mathrm{p}<.0005)$.

A significant correlation between the sketching course and the master project can't be validated; MP $(r=.178, p=.050)$. Note that the $p$-value equals the 5 per cent significant critical value.

There is no significant correlation between the results for the sketching course and the results for the theoretical courses Physics PH $(r=.113, \mathrm{p}=.219)$ and ergonomics ER $(\mathrm{r}=.154, \mathrm{p}=.092)$.

\section{Findings and discussion}

Based on the correlational study, one can observe that students with a good and excellent sketch quality are overall assessed for their product design projects with higher grades than students with minimal and adequate sketch qualities. They score higher not only for the aesthetic form-related design projects like Redesign and Form \& Colour (which may seem logical), but also for the more technical oriented design projects, like Mechanical Design and Focus on Mechanical Aspects. We note a significant correlation between sketch grades and the product design project courses Redesign, Mechanical Design, Form \& Colour, Bachelor Project and Focus on Mechanical Aspects. These courses can be considered as design projects as they would appear within the context of an industrial design office, where design challenges often rely more on creative design problem solving than on ideation or product management competences.

Several questions why students with good drawing skills score higher for design projects remain unanswered to this end. Our teaching experience taught us that most students can learn to master sufficiently well the technical aspects of free hand sketching, at least if the train enough, but are good sketch competences merely a matter of thorough training, or a sort of innate skills or personality traits that correlate with other design attributes (Song and Agogino, 2004)? Do students with already good drawing skills before they start their studies have some sort of advantage over other students, and do they keep this lead while they progress and evolve in their study? Do these students possess characteristics that will facilitate stronger and more qualitative design outcomes? Are good sketchers more motivated, more creative, do they work more accurately and with more detail? Do the better sketchers have a better spatial insight, a more developed aesthetic feeling or sense for proportion, and therefore perhaps better able to address the challenges of creating a more successful design, and thus produce better design outcomes? Or vice versa: do more motivated students or students with a better spatial insight become the better sketchers in the end? Interesting assumptions to research, but none of them can be acknowledged by this study.

There is no correlation between the sketch- and the Master Project scores. A possible explanation might be the holistic character of the Master Project course, assessing not only the product design component, but all competences an upcoming graduated product designer should master, incorporating creative, management, research, new product ideation skills, etc. The proportion of the component product design in the final grade of the Master Project is smaller, and any higher score for the design component can 
thus be evened out. Another possible explanation could be that students in their second year of the master have in one or another way succeeded in clearing their arrears to the good drawing students. There is no correlation between the sketch- and the supportive theoretical courses. The better students in sketching do not get higher grades for these courses. This finding tends to neutralize the possible impact of the generally better students.

\section{Conclusion}

One of the starting points of this paper was the question suggested by Song and Agogino (2004): 'does a student's sketching skill impact the quality of the design outcome?' Kudrowitz et al. (2012) found that the quality of sketches has a positive influence on the perception of the creativity of ideas, and MulderNijkamp and Eggink (2016) found a significant correlation between the level of quality of drawings and the success design outcomes in a brand extension industrial design project.

This correlational study examined the impact of the students' sketch quality regarding the results of six individual industrial design projects. The findings of the research question 'do better sketchers become better product designers' indicate that students with a higher quality in sketches, are more likely to produce better design outcomes in individual product design project courses. It is tempting to conclude that the better design outcomes are consequence of better sketch competences, but although we found a significant correlation between metrics (grades counted in points) of sketching and design outcomes, we can make no causal statements.

If we assume that the assessments of student design projects can be used as a benchmark for design quality, we can confirm that better sketchers become better designers in the context of an industrial design study curriculum (at least they got better assessments). Based on logical reasoning, one could argue that: If the better sketchers are assessed as better designers in an educational situation, and if the better design students become the better designers, than the better sketchers become the better designers. What this study tends to confirm, is the concept that good sketch quality has a positive impact on the quality of design outcomes.

Besides the fact that in previous studies the impact of the act of hand sketching is sufficiently supported by demonstrating correlations between sketching ability and artistic creativity (Chan and Chan, 2007; Chan and Zhao, 2010), and by the conclusion that drawing training in itself makes people more creative (Chan and Zhao, 2010), this correlational study indicates that also sketch quality is a decisive influencing factor in the assessment of design outcomes.

\section{Traditional or digital sketching?}

According to Jonson (2005), the development towards more integration of CAD in the design ideas process did not make sketching superfluous. In a multiple case study that compared how design students and design practitioners used conceptual tools in everyday design situations, he found that all the participant students considered sketching as skill, and said that they would have liked to do more sketching. Based on a study comparing the design processes of designers in both digital and traditional sketching environments, Tang et al. (2011) concluded that the digital sketching environment is similar to free-hand sketching in all significant aspects of the design process.

No research has been performed so far about the influence of sketch quality on the perceived design competences of designers in an industrial context. In industry however, it is standard procedure that design agencies hire junior designers based on a portfolio with work and drawings from their studies. This indicates at least that design agencies connect sketching skills with overall design competences. The importance of drawing in industry is supported by Schrage and Peters (2010). They state that the observations of industrial practice suggest that design success is closely linked to realizing an idea through drawing and prototyping.

The findings of this study supports the plea for integrated and well-balanced hand drawing courses (traditional or digital, and with focus on sketch quality) in industrial design and engineering design curricula. It is tempting (but probably also too simplistic) to state that if design schools want to improve the quality of their students, they should invest in hand drawing courses, and in the enhancement of students' sketch quality. 


\section{Future work}

This study was limited to only one product design curriculum. It would be interesting to research whether the same correlation could be found in other comparable programs. It would also be interesting to prove a causal link between sketch qualities and design qualities in a study that goes beyond analyzing correlations between courses. This would enable us to find ways to improve students' sketch quality, and to determine which sketch training or courses are the most effective ones. Another possible future study could focus on the quality of the ideas and the quality of the drawings in design projects separately, to research possible correlations between quality of ideas and quality of drawings, and thus uncoupling some of the assumptions made in this study. It would also be interesting to study the impact of sketch quality of designers in industry, or to find out if qualitative sketch competences are a decisive factor in recruitment.

\section{References}

Ainsworth, S., Prain, V. and Tytler, R. (2011), "Drawing to learn in Science”, Science, Vol. 333 No. 6046, pp. 1096-1097. https://doi.org/10.1126/science.1204153

Alvarez, A. (2004), Techniques of Scott Robertson 1: Basic Perspective Form Drawing. [Motion Picture].

Bilda, Z. and Demirkan, H. (2003), "An insight on designer's sketching activities in traditional versus digital media”, Design Studies, Vol. 24 No. 1, pp. 27-50. https://doi.org/10.1016/S0142-694X(02)00032-7

Casakin, H. and Goldschmidt, G. (1999), "Expertise and the use of visual analogy: implications for design education”, Design Studies, Vol. 20 No. 2, pp. 153-175. https://doi.org/10.1016/S0142-694X(98)00032-5

Chan, D.W. and Chan, L.K. (2007), "Creativity and drawing abilities of Chinese students in Hong Kong: is there a connection", New Horizons in Education, Vol. 55 No. 3, pp. 77-94.

Chan, D. and Zhao, Y. (2010), "The relationship between drawing skill and artistic creativity: do age and artistic involvement make a difference?", Creativity Research Journal, Vol. 22 No. 1, pp. 27-36. https://doi.org/10.1080/10400410903579528

Christiaans, H. (2002), “Creativity as a design criterion”, Creativity Research Journal, Vol. 14 No. 1, pp. 41-54. https://doi.org/10.1207/S15326934CRJ1401_4

Dillon, M.R. (2010), "Dynamic Design: Cognitive Processes in Design Sketching”, Indiana Undergraduate Journal of Cognitive Science, Vol. 5, pp. 28-43.

Eissen, K. and Steur, R. (2007), Sketching: Drawing Techniques for Product Designers, BIS Publishers, Amsterdam.

Goldschmidt, G. (1991), “The dialectics of sketching”, Creativity Research Journal, Vol. 4 No. 2, pp. $123-143$. https://doi.org/10.1080/10400419109534381

Horn, D. and Salvendy, G. (2009), "Measuring consumer perception of product creativity: impact on satisfaction and purchaseability", Human Factors and Ergonomics in Manufacturing, Vol. 19 No. 3, pp. 223-240. https://doi.org/10.1002/hfm.20150

Jonson, B. (2005), "Design ideation: the conceptual sketch in the digital age”, Design Studies, Vol. 26 No. 6, pp. 613-624. https://doi.org/10.1016/j.destud.2005.03.001

Jonsson, A. and Svingby G. (2007), "The use of scoring rubrics: Reliability, validity and educational consequences", Educational Research Review, Vol. 2 No. 2, 2007, pp. 130-144. https://doi.org/10.1016/j.edurev.2007.05.002

Kavakli, M. and Gero, J.S. (2001), "Sketching as a mental imagery processing", Design Studies, Vol. 22 No. 4, pp. 347-364. https://doi.org/10.1016/S0142-694X(01)00002-3

Kudrowitz, B.M. and Wallace, D. (2013), "Assessing the quality of ideas from prolific, early-stage product ideation”, Journal of Engineering Design, Vol. 24 No. 2, pp. 120-139. https://doi.org/10.1080/09544828.2012.676633

Kudrowitz, B., Te, P. and Wallace, D. (2012), "The influence of sketch quality on perception of product-idea creativity”, Artificial Intelligence for Engineering Design, Analysis and Manufacturing, Vol. 26 No. 3, pp. 267- 279. https://doi.org/10.1017/S0890060412000145

Kurosu, M. and Kashimura, K. (1995), "Apparent usability vs. inherent usability: experimental analysis on the determinants of the apparent usability", Conference companion on Human factors in computing systems Denver, Colorado, May 7-11, 1995, ACM, New York, pp. 292-293. https://doi.org/10.1145/223355.223680

Norman, D.A. (2002), "Emotion and design: Attractive things work better”, Interactions Magazine, Vol. 9 No. 4 , pp. 36-42. https://doi.org/10.1145/543434.543435

Leard Statistics (2013), One-way ANOVA. [online] Lund Research ltd. Available at: https://statistics.laerd.com/statistical-guides/one-way-anova-statistical-guide.php (accessed 03.09.2016). 
Menezes, A. and Lawson, B. (2006), “How designers perceive sketches”, Design Studies, Vol. 27 No. 5, pp. 571585. https://doi.org/10.1016/j.destud.2006.02.001

Mulder-Nijkamp, M. and Eggink, W. (2016), "Design-Research-in-Education; combining the best of both worlds", Proceedings of the $18^{\text {th }}$ International Conference on Engineering and Product Design Education, Design Education: Collaboration and Cross-Disciplinarity, Aalborg, Denmark, September 8-9, 2016, pp. $192-197$.

Olofsson, E. and Sjolen, K. (2005), Design Sketching, Klippan, Design Books AB, Sweden.

Pearson, D., Logie, R.H. and Green C. (1996), "Mental manipulation, visual working memory and executive processes", Psychologische Beitrage, Vol. 38 No. 3-4, pp. 324-342.

Purcell, A.T. and Gero, J.S. (1998), "Drawing and the design process", Design Studies, Vol. 19 No. 4, pp. 389430. https://doi.org/10.1016/S0142-694X(98)00015-5

Rodgers, P.A., Green, G. and McGown, A. (2000), "Using concept sketches to track design progress", Design Studies, Vol. 21 No. 5, pp. 451-464. https://doi.org/10.1016/S0142-694X(00)00018-1

Rohde, M. (2011), Sketching, the Visual Power Tool. [online] Available at: http://alistapart.com/article/sketchingthe-visual-thinking-power-tool (accessed 04.10.2015).

Schrage, M. and Peters, T. (2010), Serious Play: How the World's Best Companies Simulate to Innovate, Harvard Business School Press, Boston, MA.

Schütze, M., Sachse, P. and Römer, A. (2003), "Support value of sketching in the design process", Research in Engineering Design, Vol. 14 No. 2, pp. 89-97. https://doi.org/10.1007/s00163-002-0028-7

Song, S. and Agogino, A.M. (2004), "Insights on designers' sketching activities in product design teams", Proceedings of ASME 2004 International Design Engineering Technical Conferences and Computers and Information in Engineering Conference, Vol. 3a, Salt Lake City, USA, September 28-October 2, 2004, ASME, pp. 351-360. https://doi.org/10.1115/DETC2004-57474

Suwa, M. and Tversky, B. (1997), "What do architects and students perceive in their design sketches? A protocol analysis”, Design Studies, Vol. 18 No. 4, pp. 385-403. https://doi.org/10.1016/S0142-694X(97)00008-2

Suwa, M., Gero, J.S. and Purcell, T. (1998a), "The roles of sketches in early conceptual design processes", Proceedings of Twentieth Annual Meeting of the Cognitive Science Society, Lawrence Erlbaum, Hillsdale, New Jersey, pp. 1043-1048.

Suwa, M., Purcell, T. and Gero, J.S. (1998b), "Macroscopic analysis of design processes based on a scheme for coding designers' cognitive actions", Design Studies, Vol. 19 No. 4, pp. 455-483. https://doi.org/10.1016/S0142-694X(98)00016-7

Tang, H.H., Lee, Y.Y. and Gero, J.S. (2011), "Comparing collaborative co-located and distributed design processes in digital and traditional sketching environments: A protocol study using the function-behaviourstructure coding scheme", Design Studies, Vol. 32 No. 1, pp. 1-29. https://doi.org/10.1016/j.destud.2010.06.004

Tractinsky, N. (1997), “Aesthetics and Apparent Usability: Empirically Assessing Cultural and Methodological Issues", Proceedings of the SIGCHI conference on Human factors in computing systems, Atlanta, USA, March 22-27, 1997, ASME, pp. 115-122. https://doi.org/10.1145/258549.258626

Ullman, D.G., Wood, S. and Craig, D. (1990), "The importance of drawing in the mechanical design process", Computers \& Graphics, Vol. 14 No. 2, pp. 263-274. https://doi.org/10.1016/0097-8493(90)90037-X

van der Lugt, R. (2003), "Relating the quality of the idea generation process to the quality of the resulting design ideas", Proceedings of the $14^{\text {th }}$ International Conference on Engineering Design, Stockholm, Sweden, August 19-21, 2003, The Design Society, Glasgow, pp. 19-21.

Verstijnem, I.M., van Leeuwen, C., Goldschmidt, G., Hamel, R. and Hennessey, J.M. (1998), "Sketching and creative discovery", Design Studies, Vol. 19 No. 4, pp. 519-546. https://doi.org/10.1016/S0142694X(98)00017-9

Waanders, R., Eggink, W. and Mulder-Nijkamp, M. (2011), "Sketching is more than making correct drawings", Proceedings of the international conference on engineering and product design education, London, UK, September 8- 9, 2011, The Design Society, London, pp. 299-304.

Yang, M.C. and Cham, J.G. (2007), "An analysis of sketching skill and its role in early stage engineering design", Journal of Mechanical Design, Vol. 129 No. 5, pp. 476-482. https://doi.org/10.1115/1.2712214

Jan A.M. Corremans, Associate Professor

University of Antwerp, Faculty of Design Sciences - Product Development

Ambtmanstraat 1, 2000 Antwerp, Belgium

Email: jan.corremans@uantwerpen.be 